\title{
BMJ Open Impact of health insurance on healthcare utilisation patterns in Vietnam: a survey-based analysis with propensity score matching method
}

\author{
Nguyen Thi Thu Thuong
}

To cite: Thuong NTT. Impact of health insurance on healthcare utilisation patterns in Vietnam: a survey-based analysis with propensity score matching method. BMJ Open 2020;10:e040062. doi:10.1136/ bmjopen-2020-040062

- Prepublication history and additional material for this paper are available online. To view these files, please visit the journal online (http://dx.doi. org/10.1136/bmjopen-2020040062).

Received 06 May 2020 Revised 25 August 2020 Accepted 05 September 2020

A Check for updates

(C) Author(s) (or their employer(s)) 2020. Re-use permitted under CC BY-NC. No commercial re-use. See rights and permissions. Published by BMJ.

Faculty of Economics, TNUUniversity of Economics and Business Administration, Thai Nguyen, 250000, Vietnam

Correspondence to Dr Nguyen Thi Thu Thuong, Faculty of Economics, TNUUniversity of Economics and Business Administration, Thai Nguyen, Vietnam; nttthuong@tueba.edu.vn

\section{ABSTRACT}

Objectives The study aims to evaluate the impact of the Revised Health Insurance Law 2014 on the utilisation of outpatient and inpatient care services, healthcare services utilisation at different levels of providers, types of providers and types of visits across different entitlement groups. Design/setting Secondary data from two waves of the Vietnam Household Living Standard Survey (VHLSS) 2016, VHLSS 2014 were used. A cross-sectional study applying propensity score matching was conducted.

Participants A total of 4900 individuals who reported using healthcare services are analysed.

Outcomes measure Numbers of outpatient and inpatient visits, frequency of healthcare service utilisation at commune health stations, district hospitals, provincial hospitals, public and private health facilities, number of visits at health facility for medical treatment and health checks per year.

Results The result indicates that health insurance (HI) policy increased the number of outpatient visits for the enrolled between 0.87 and 1.29. The greatest impact was found on participants of heavily subsidised health insurance $(\mathrm{HSHI})$ programmes with 1.29 visits per person per year. Similarly, an increase between 0.08 and 0.16 in the number of inpatient admissions was because of participation in $\mathrm{HI}$. With regard to type of healthcare providers, the study found that participation in $\mathrm{HI}$ has the most effect on the use of healthcare services at district hospitals. However, the study demonstrated that the impacts of $\mathrm{HI}$ on the increase in the frequency of visiting commune health stations, number of visits at the provincial hospital for HSHI groups, and number of visits at health facilities for health check and consultation were sensitive to unobserved characteristics.

Conclusion Our findings imply that policy-makers in Vietnam could continue expanding health insurance coverage to increase access to healthcare services for citizens, especially vulnerable groups. In addition, the government should draw more attention to primary healthcare level.

\section{INTRODUCTION}

Access to basic healthcare services plays an important role in the development of nations and the overall well-being of people. Healthcare is considered an essential need and also
Strengths and limitations of study

- This is the first comprehensive study to assess the impact of health insurance on healthcare utilisation patterns in Vietnam after the Revised Health Insurance Law 2014 has been introduced.

- The data are derived from the large population sample size-Vietnam Household Living Standard Survey (VHLSS), which can be regarded as representative of the overall population. The findings can be generalised to the Vietnam population and provide valuable experience for other low-income and middle-income countries.

- The study used secondary data from the VHLSS survey; therefore, some factors would be useful for evaluating the impact of health insurance, such as supply-side factors, and health security was not included in the dataset. There might also be recall bias related to self-reported data.

- Using the propensity score matching method to measure the causal effect, the estimated results may be biased if unobserved confounders affect both the outcome and treatment variables. Besides, the interval after the revision of the law may have been short to evaluate its impacts.

a basic human right. ${ }^{1}$ However, in low-income and middle-income countries (LMICs) where poverty and inequalities affect health status and hinder the provision of and access to healthcare, accessibility to healthcare services remains highly restricted. ${ }^{1}$ Accordingly, LMICs' governments have sought to accelerate progress towards Universal Health Coverage (UHC) by introducing and expanding non-profit health insurance (HI) schemes to increase healthcare coverage and financial protection. ${ }^{23}$

Vietnam has gained remarkable achievements in increasing HI coverage reaching above $85 \%$ in 2017. Although the HI coverage rate is high among high-income and low-income groups, including the civil servants and the poor, the figures for the 


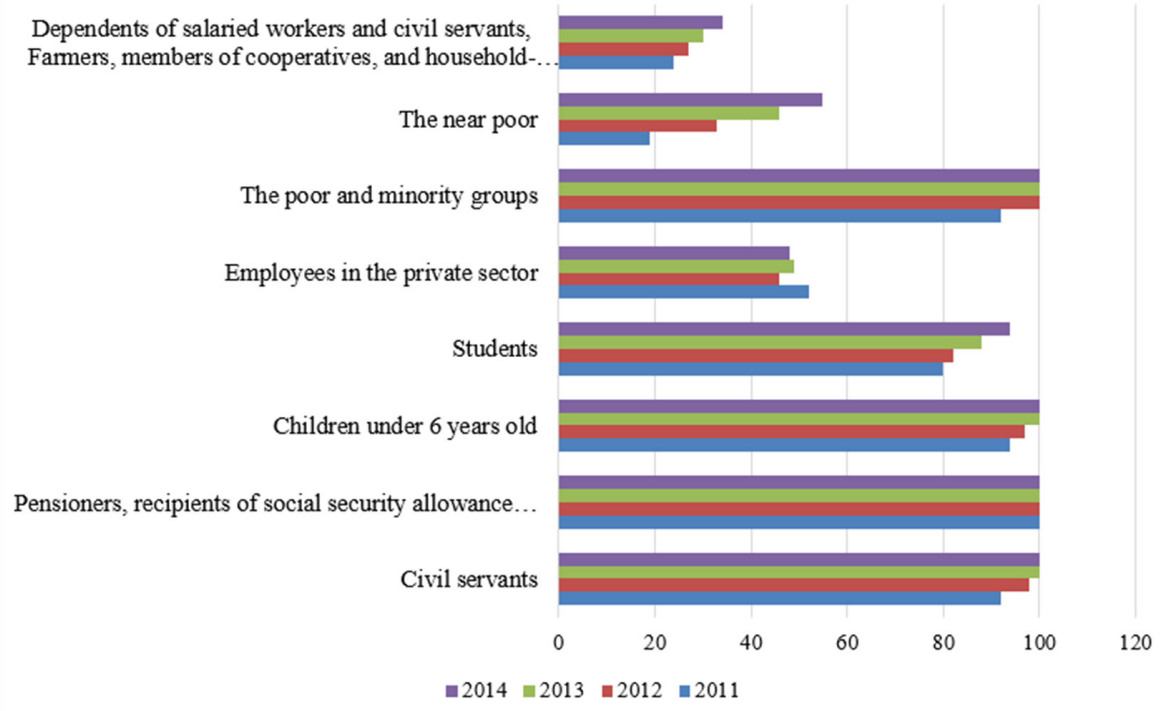

Figure 1 Trends of health insurance coverage among different groups in Vietnam. ${ }^{56}$

informal sector and the near-poor are still low (figure 1). Reaching these groups is a major challenge for Vietnam, and they should be focused to achieve UHC by $2025 .{ }^{5}$

Vietnam is facing many challenges to achieve the goal of UHC by 2025 . First, approximately $15 \%$ of the population does not have any form of financial protection, such as HI. Most out-of-pocket health expenditures (OOP) are paid for inpatient medical services $(55.8 \%)$ and selfmedication $(43.7 \%) .{ }^{56}$ Second, the rate of using HI cards among the insured when visiting health facilities is still modest, with $60 \%-70 \%$ for outpatient care and only $40 \%$ for inpatient admission in 2013, except for the insured of the poorest quintile group. ${ }^{6}$ The reason might be that before introducing the Revised Health Insurance Law in 2014, the insured must go to the medical facilities specified on the insurance card; otherwise, they have to pay all medical expenses. As a result, patients with severe conditions often skip grassroots level facilities and go directly to central or specialised hospitals without following the referral process, and do not use the HI card. Third, patients often visit private health facilities for outpatient care (about 34\%), which are not covered by HI or do self-treatment. ${ }^{67}$ The reasons for this tendency can be long waiting time and attitude towards patients of health workers. ${ }^{8}$ Consequently, they might incur high OOP. Fourth, the rate of using healthcare services at a higher level of providers increases, whereas this rate tends to decrease at a lower level, leading to overcrowding at tertiary hospitals. In particular, the rate of outpatient services utilisation at hospitals in 2014 was $43.1 \%$, higher than the rate of $28.8 \%$ in 2006 . The rate of inpatient visits at these facilities also increased, reaching $85.7 \%$ in 2014 , compared with $78.1 \%$ in 2006 . However, the frequency of outpatient visits at commune health stations decreased from $25.9 \%$ in 2006 to $20.2 \%$ in $2014 .^{9}$ The barriers to low uptake of services at the grassroots level facilities are likely to be associated with the quality of medical services, equipment, lack of essential medicines, and low qualifications of health workers. ${ }^{10}$ Last but not least, there is inequality in the pattern of visiting health facilities between rural and urban areas, between the rich and the poor, and ethnicity. ${ }^{7}$ Poor households of ethnic minorities are more likely to visit commune health stations than provincial hospitals (67\% vs $2 \%)$. However, the non-poor frequently seek care at provincial/central hospitals $(14 \%)$. $^{7}$

Therefore, like many LMICs, Vietnam has approved $\mathrm{HI}$ as one of the possible options to achieve the UHC goal. In 2014, the Revised HI Law in Vietnam had been introduced and officially took effect from January 2015. Table 1 presents the summary of the Revised HI Law and its major changes. ${ }^{6} 1112$

Although a large and growing body of literature has been done to examine the impact of HI on healthcare services utilisation in LMIC, findings from the studies are still inconsistent. ${ }^{13}$ The positive impact of $\mathrm{HI}$ on access and usage of medical services has been demonstrated in the studies of Hangoma et al, ${ }^{14}$ Balamiento, ${ }^{1}$ Zhao $^{15}$ and Sparrow et al. ${ }^{16}$ However, the study on the impact of medical insurance for the poor in Georgia indicated that there was no impact of the programme on the utilisation of health services. ${ }^{17}$ Similarly, a study by Thornton et al about the effect of social security HI for the informal sector workers in Nicaragua found that there was no increase in the use of services among the newly insured. ${ }^{18}$ This inconsistency may be because these empirical studies were carried out in different settings with different health financing mechanisms and citizens' health-seeking behaviours.

In Vietnam, Wagstaff ${ }^{19}$ found that the HI programme for the poor had no impact on healthcare utilisation, while Sepehri $e t a l^{20}$ investigated that the insured had a higher length of hospital stay than those without insurance. Also, Nguyen showed that voluntary health insurance 
Table 1 Health insurance of target groups in Vietnam after adopting revised HI Law

\begin{tabular}{|c|c|c|c|}
\hline Target groups & Description & Premium and subsidies & Co-payment rate \\
\hline $\begin{array}{l}\text { First group-contributions are made } \\
\text { by employees and employers }\end{array}$ & $\begin{array}{l}\text { Employees with an indefinite term } \\
\text { labour contract, and those signing } \\
\text { labour contracts from } 3 \text { months or } \\
\text { more } \\
\text { Employers of enterprises } \\
\text { Civil servants and public employees }\end{array}$ & $\begin{array}{l}4.5 \% \text { of payroll tax ( } 3 \% \text { employers, } \\
1.5 \% \text { employees) }\end{array}$ & $20 \%$ \\
\hline $\begin{array}{l}\text { Second group-contributions are } \\
100 \% \text { subsidised by the government }\end{array}$ & $\begin{array}{l}\text { People from poor households, and } \\
\text { those from ethnic minority } \\
\text { People living in areas with difficult } \\
\text { socioeconomic conditions } \\
\text { Meritorious people } \\
\text { Children under } 6 \text { years old } \\
\text { People serving in the army and the } \\
\text { police }\end{array}$ & $\begin{array}{l}100 \% \text { subsidy by the government } \\
\text { (the premium contribution is equal to } \\
4.5 \% \text { of the monthly salary, or } 4.5 \% \\
\text { of minimum salary depending on each } \\
\text { target group) }\end{array}$ & $\begin{array}{l}\text { Reduced from } 5 \% \text { to } 0 \% \\
\text { (exempted from co-payment } \\
\text { and are entitled to use free } \\
\text { medical examination and } \\
\text { treatment services) }\end{array}$ \\
\hline $\begin{array}{l}\text { Third group-contributions are partly } \\
\text { subsidised by the government }\end{array}$ & The near-poor & $\begin{array}{l}\text { Minimum subsidy level is } 70 \% \text { of } \\
\text { minimum salary }\end{array}$ & Reduced from $20 \%$ to $5 \%$ \\
\hline \multirow{3}{*}{$\begin{array}{l}\text { Fourth group-contributions are paid } \\
\text { by social insurance fund }\end{array}$} & - Retirees & - $4.5 \%$ of monthly pension & $20 \%$ \\
\hline & $\begin{array}{l}\text { People receiving monthly social } \\
\text { insurance benefits due to labour } \\
\text { accidents, occupational diseases }\end{array}$ & - $4.5 \%$ of minimum salary & $20 \%$ \\
\hline & $\begin{array}{l}\text { Female employees are on leave } \\
\text { during maternity regime }\end{array}$ & $\begin{array}{l}4.5 \% \text { of the monthly salary before } \\
\text { the maternity leave }\end{array}$ & $20 \%$ \\
\hline $\begin{array}{l}\text { Fifth group-contributions are based } \\
\text { on unit subscription of the family }\end{array}$ & Informal sector & $\begin{array}{l}\text { The first person contributes a } \\
\text { premium of } 4.5 \% \text { of minimum } \\
\text { salary } \\
\text { The second person pays } 70 \% \text { of } \\
\text { the of the first person's contribution } \\
\text { The third person pays } 60 \% \text { of the } \\
\text { first person's contribution } \\
\text { The fourth person contributes } 50 \% \\
\text { of the first person's contribution } \\
\text { The fifth person pays } 40 \% \text { of the } \\
\text { first person's contribution }\end{array}$ & $20 \%$ \\
\hline Before 2014 & $30 \%$ & $40 \%$ & $60 \%$ \\
\hline \multirow[t]{2}{*}{ After 2014} & $0 \%$ & $40 \%$ & $60 \%$ \\
\hline & $100 \%$ for outpatient care & & \\
\hline
\end{tabular}

\section{Provider payment method}

Capitation (application for primary health facilities).

Fee-for-service (FFS) - prevalent method in Vietnam.

Case-based diagnostic-related groups (DRGs) - being tested in several provinces.

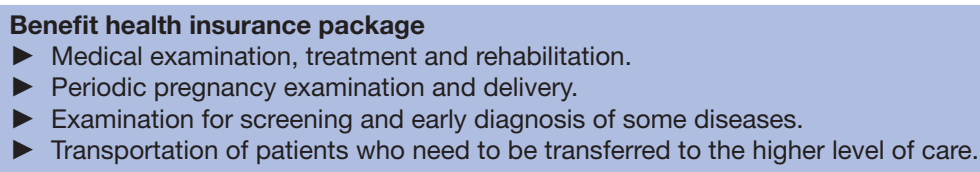

(VHI) increased outpatient and inpatient visits among the enrollees. ${ }^{21}$ Likewise, a recent study conducted by Nguyen found that there was a positive impact of student $\mathrm{HI}$ on the frequency of healthcare visits. ${ }^{22}$ However, these studies did not evaluate the effects of $\mathrm{HI}$ on healthcare utilisation at different levels of providers, type of providers and type of visits. In addition, although in Vietnam, a considerable amount of literature has been published on evaluating the impact of non-profit HI programmes on the utilisation of healthcare services, the research results are not always consistent.

To my knowledge, in Vietnam, until now, there has been no comprehensive study evaluating the impact of the Revised HI Law in 2014 on healthcare utilisation patterns, including frequency of outpatient and inpatient visits, health facilities utilisation (community health centres, district hospital, public and private health facilities) and types of visiting health facilities (treatment or 
consultation and health check). Therefore, evaluating the HI policy effects on healthcare services utilisation for making recommendations to improve the HI scheme and strengthening the health system is imperative. Furthermore, findings from the present study might offer policymakers not only in Vietnam but also in LMIC useful information to improve the HI scheme making healthcare services available and affordable to citizens, especially disadvantaged people.

\section{METHODS}

\section{Sampling and data source}

A cross-sectional study was conducted to assess the impact of the HI policy on the use of healthcare services. The study used the data from the Vietnam Household Living Standards Survey (VHLSS) 2016 and VHLSS 2014. The surveys were carried out every 2 years by the General Statistics Office of Vietnam (GSO) with technical assistance and funding from the World Bank. The VHLSS 2014 included 9399 households and 35920 individuals from 3130 communes. The VHLSS 2016 embraced 9399 households with 35793 individuals selected from 3133 communes in which $50 \%$ of the enumeration areas were selected from the VHLSS 2014, and 50\% were newly selected from the master sample. The pre-treatment (pre-programme) characteristics of the insured and noninsured were obtained from the VHLSS 2014, whereas the outcomes and treatment variables were derived from VHLSS 2016. I included only individuals who reported outpatient and/or inpatient visits in the last 12 months. Thus, the number of observations in this study reduced sustainably and included 4900 individuals.

The survey collected enormous information on households in Vietnam. However, in this study, we used data related to incomes and household expenditures, including expenses for food, clothing, accommodation, education, health and other expenses. Other information such as demographic characteristics (age, gender, ethnicity, marital status); education; occupation; and electricity, water, and sanitary conditions were extracted from the survey. Data related to health status, health insurance enrolment of household members, number of outpatient and inpatient visits, and reasons for visiting different health facilities were also used.

\section{Definition of variables}

Control group includes individuals who are non-insured in 2016.

\section{Treatment groups}

To evaluate whether the impacts of the HI scheme on a number of outcome variables are heterogeneous across the entitlement categories, and to lessen the possibility of mismatching, we divided the insured into two subgroups, classified as voluntary health insurance (VHI) subsample and heavily subsidised health insurance (HSHI) subsample (the poor, the near-poor, policy beneficiaries) based on the amendments of HI policy. Students' VHI is not part of the VHI subsample. The full sample includes all individuals having HI. The treatment groups are those who have HI in 2016.

\section{Outcome variables}

I assess the HI scheme's impact on the frequency of outpatient and inpatient visits. In addition, the study aims to point out whether amendments in HI policy, such as allowing admission at the tertiary level without a referral letter, affect the intensity of visiting health facilities at different providers' levels. Also, the effect of the HI on the frequency of healthcare utilisation at public and private health facilities was evaluated. Besides, the study examines the impact of the scheme on types of visits, including the intensity of using medical facilities for treatment and health check-up.

\section{Explanatory variables}

To ensure that explanatory variables are exogenous with HI participation, the covariates in 2014 VHLSS were used instead of 2016 VHLSS-pre-treatment variables. ${ }^{21}$ 23-25 Explanatory variables should contain covariates which affect simultaneously the treatment (enrolment) status and the outcomes of interest. ${ }^{26}$

Explanatory variables including education level, age groups, sex, gender, marital status, ethnicity, occupation status, availability of clean water, electricity, access to toilet, household size, a household composition such as the number of children under 6 years of age and number of elderly are controlled for. Besides, expenditure quintiles; HI status; the number of motorcycles, telephones, radios, TVs or computers; and a residential area owned by households are selected. Importantly, illness status, number of illness times and days per year are also controlled in different specifications. In addition, covariates include seven socioeconomic regions of Vietnam and places of residence (rural or urban). These control variables have been used in a large and growing volume of public studies. ${ }^{1519212427-29}$ The definition of variables is provided in online supplemental appendix 1.

\section{Statistical analysis}

When evaluating policies, we encounter selection bias problems, which means that enrolment in HI scheme is not random for some groups such as the informal sector workers, the farmers, the elderly or the near-poor due to the voluntary nature per se of the programme. ${ }^{23} 3031$ There are confounding factors that may affect the participation in HI. If these characteristics are systematically correlated with the outcome variables, it may lead to biased estimates. ${ }^{23}{ }^{24}$ For instance, potential health risks, age and income can simultaneously affect demands for health services and health insurance enrolment. ${ }^{124}$ This may result in overestimation or underestimation of the impact of the HI programme. Although we do not face the self-selection problem in estimating the effect of the 
HI programme on the poor, the assignment is not random because they are selected through predefined criteria. ${ }^{32}$

The effect of the HI scheme can be estimated by comparing the use of health services when people join HI and when they do not participate. However, it is difficult to estimate this effect in observational research because we do not know how the insured would have used medical services if they had not enrolled in HI. Accordingly, we employed the propensity score matching (PSM) method, which was introduced by Rosenbaum and Rubin ${ }^{33}$ to address this problem. This method was applied in a number of studies such as Mebratie et al, ${ }^{24}$ GustafssonWright et al, ${ }^{34}$ Palmer, ${ }^{35}$ Nguyen ${ }^{21}$ and Axelson et al. ${ }^{27}$ The PSM builds a statistical comparison group based on the likelihood of involving in the HI programme, depending on the observed traits. ${ }^{23}$ The idea of PSM is to find individuals not participating in the programme whose characteristics are similar to those of the participants. These characteristics are not affected by the programme, for example, preprogramme characteristics. ${ }^{23}$ The PSM is based on two assumptions.

First, participation in the programme is completely based on observable features, which is called unconfoundedness $^{23}$ :

$$
\left(\mathrm{Y}_{\mathrm{i}}^{\mathrm{T}}, \mathrm{Y}_{\mathrm{i}}^{\mathrm{C}}\right) \perp \mathrm{T}_{\mathrm{i}} \mid \mathrm{X}_{\mathrm{i}}
$$

where $T_{i}$ is treatment variable, $T_{i}=1$ if the individual participates in the HI programme, $T_{i}=0$ otherwise. $Y_{i}^{T}$, $Y_{i}^{C}$ stand for outcome variables of interest for the enrolled (treatment group) and the non-enrolled (control group); $X_{i}$ presents covariates affecting both self-selection and outcome variables.

The second assumption is common support, which is the area where the propensity scores of both the treatment group and control group are estimated. It is assumed that the probability of enrolment, conditional on the covariates $\mathrm{X}$ belongs to 0 and $1,0<P\left(T_{i}=1 \mid X_{i}\right)<1 .{ }^{23}$ Every enrolled individual will be compared with the corresponding non-enrolled which has the same propensity scores; then the average difference in outcomes between two groups is calculated to determine the impact of the policy. This effect is the average treatment effect on the treated (ATT). The ATT can be defined as follows ${ }^{23}$ :

$$
\operatorname{ATT}_{\mathrm{PSM}}=\mathrm{E}_{\mathrm{P}(\mathrm{X}) \mathrm{IT}=1}\left\{\mathrm{E}\left[\mathrm{Y}_{\mathrm{i}}^{\mathrm{T}} \mathrm{TT}_{\mathrm{i}}=1, \mathrm{P}(\mathrm{X})\right]-\mathrm{E}\left[\mathrm{Y}_{\mathrm{i}}^{\mathrm{C}} \mathrm{T}_{\mathrm{i}}=\mathrm{z}, \mathrm{P}(\mathrm{X})\right]\right\}
$$

where $P(X)$ represents propensity scores, given the observed characteristics of participants and nonparticipants, which are estimated from logit regression in this study.

Supposed that ATT on the number of outpatient visits is 1.25 , we can interpret that after matching treated and control individuals, the HI programme's effect is to increase the number of outpatient visits by 1.25 . In other words, people who participate in HI make greater outpatient care use than those who did not enrol in the HI programme.

The World Bank suggests that, identically, to calculate the propensity score and match the participants and non-participants based on the propensity score, pre-programme data should be used. ${ }^{23}$ Therefore, preprogramme baseline data (VHLSS 2014) on the insured and non-insured were used to calculate the propensity scores and match them. I used different matching estimators to check the robustness of estimation results, including nearest-neighbour matching $(\mathrm{NN})$, kernel matching and radius calliper matching. The calliper was determined by dividing the SD of the propensity score by $4 .^{36}$ I used the bandwidths of 0.04 , which was applied in the study of Palmer for this study. ${ }^{35}$

STATA software (V.14) was used to extract, merge data and estimate results.

\section{Patient and public involvement}

Patients were not involved in this study.

\section{RESULTS}

\section{Estimated effects of health insurance reform on healthcare} utilisation outcomes

The descriptive statistics and the means comparison tests between the insured and the uninsured regarding characteristics that may affect both the probability of enrolling in different HI programmes and the outcome variables are provided in table 2. Descriptive statistics showed significant differences in a number of factors across the participating and non-participating HI groups. The statistical description of patterns in utilisation of health services at different health facilities for the non-insured group and different HI subsamples of interest is provided in table 3. Similarly, there were also differences in a range of outcome variables across different groups.

To calculate the propensity scores, I estimated the factors affecting the probability of enrolling in the HI scheme by using a logit model for different treatment and control groups (online supplemental appendix 2). The results indicated that variables influencing the probability of joining the HI programme varied depending on the treatment subsamples. In general, age, gender, ethnicity, marital status, education level, occupation, household size, household composition, expenditure, assets, number of illness days and place of residence were factors determining the odds of participating in the HI scheme.

Table 4 shows the ATTs of the HI scheme for a range of outcomes across different subpopulations. There was a statistically significant positive impact of the policy on the frequency of using outpatient health services across all subpopulations. The estimated results showed that the HI policy increased the number of outpatient visits for the enrolled between 0.87 and 1.29. The greatest impact was found on participants of HSHI programmes with 1.29 visits per person per year (with NN matching). Similarly, an increase between 0.08 and 0.16 in the number of inpatient admissions was because of participation in HI. The largest increase in the frequency of using inpatient care services among the insured of the poor, nearpoor or policy beneficiaries was due to the policy $(0.16$ 
Table 2 Descriptive statistics across different treatment and control groups before matching

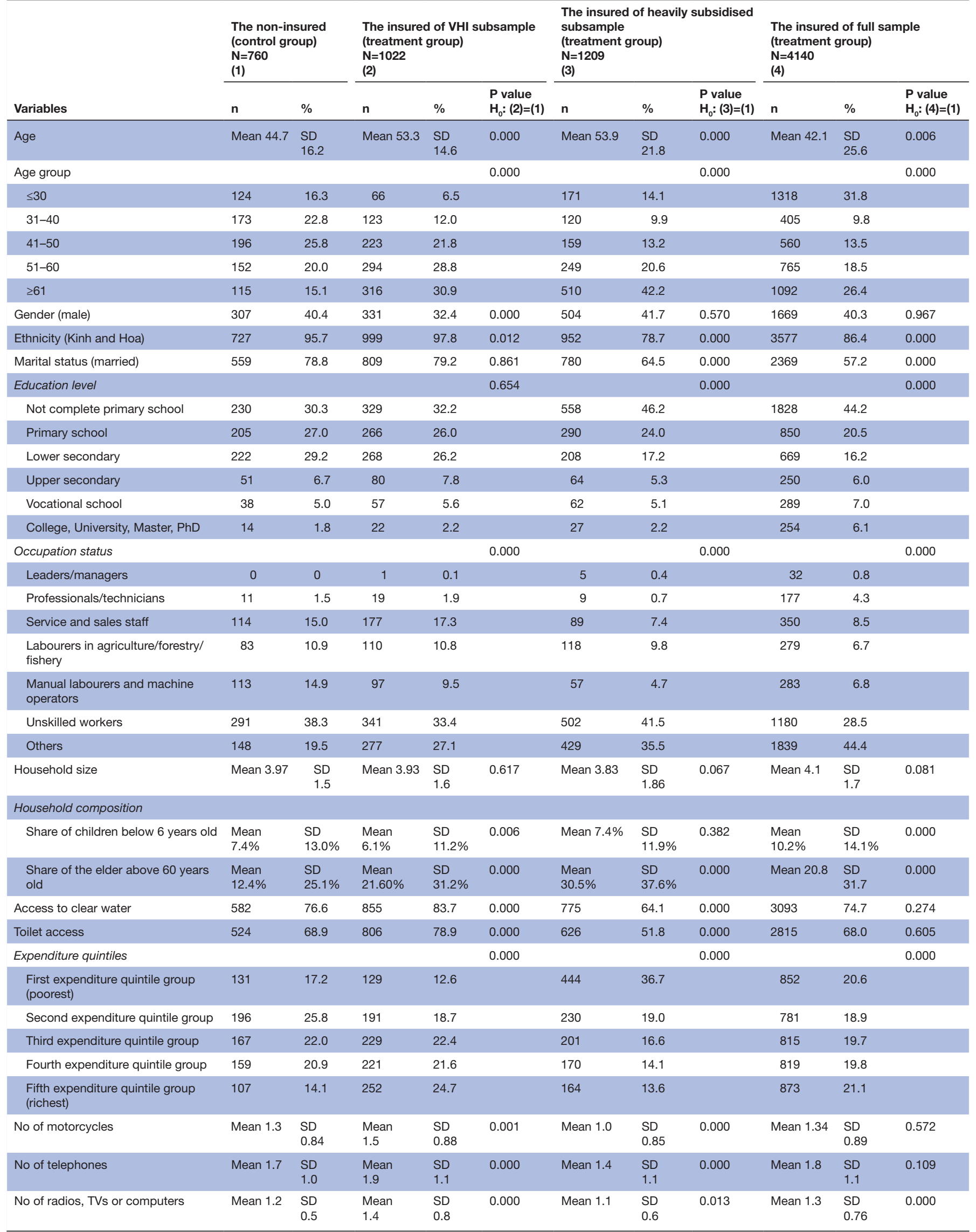


Table 2 Continued

\begin{tabular}{|c|c|c|c|c|c|c|c|c|c|c|c|}
\hline \multirow[b]{2}{*}{ Variables } & \multicolumn{2}{|c|}{$\begin{array}{l}\text { The non-insured } \\
\text { (control group) } \\
\mathrm{N}=760 \\
\text { (1) }\end{array}$} & \multicolumn{3}{|c|}{$\begin{array}{l}\text { The insured of VHI subsample } \\
\text { (treatment group) } \\
\mathrm{N}=1022 \\
(2)\end{array}$} & \multicolumn{3}{|c|}{$\begin{array}{l}\text { The insured of heavily subsidised } \\
\text { subsample } \\
\text { (treatment group) } \\
\mathrm{N}=1209 \\
\text { (3) }\end{array}$} & \multicolumn{3}{|c|}{$\begin{array}{l}\text { The insured of full sample } \\
\text { (treatment group) } \\
\mathrm{N}=4140 \\
\text { (4) }\end{array}$} \\
\hline & $\mathbf{n}$ & $\%$ & $\mathbf{n}$ & $\%$ & $\begin{array}{l}P \text { value } \\
H_{0}:(2)=(1)\end{array}$ & $\mathbf{n}$ & $\%$ & $\begin{array}{l}P \text { value } \\
H_{0}:(3)=(1)\end{array}$ & $\mathbf{n}$ & $\%$ & $\begin{array}{l}\text { P value } \\
H_{0}:(4)=(1)\end{array}$ \\
\hline Total residential area $\left(\mathrm{m}^{2}\right)$ & Mean 81.2 & $\begin{array}{l}S D \\
45.1\end{array}$ & $\begin{array}{l}\text { Mean } \\
90.4\end{array}$ & $\begin{array}{l}\text { SD } \\
59.2\end{array}$ & 0.000 & Mean 74.0 & $\begin{array}{l}\text { SD } \\
45.9\end{array}$ & 0.000 & Mean 84.4 & $\begin{array}{l}\text { SD } \\
53.9\end{array}$ & 0.128 \\
\hline Illness status in last 12 months & 85 & 11.2 & 209 & 20.4 & 0.000 & 289 & 23.9 & 0.000 & 759 & 18.3 & 0.000 \\
\hline No of illness times in last 12 months & Mean 0.16 & $\begin{array}{l}\text { SD } \\
0.55\end{array}$ & Mean 0.36 & $\begin{array}{l}\text { SD } \\
0.9\end{array}$ & 0.000 & Mean 0.5 & $\begin{array}{l}\text { SD } \\
1.4\end{array}$ & 0.000 & Mean 0.34 & $\begin{array}{l}\text { SD } \\
1.08\end{array}$ & 0.000 \\
\hline No of illness days in last 12 months & Mean 1.52 & $\begin{array}{l}\text { SD } \\
9.82\end{array}$ & $\begin{array}{l}\text { Mean } \\
5.05\end{array}$ & $\begin{array}{l}\text { SD } \\
24.8\end{array}$ & 0.000 & Mean 4.98 & $\begin{array}{l}\text { SD } \\
14.4\end{array}$ & 0.000 & Mean 4.38 & $\begin{array}{l}\text { SD } \\
19.7\end{array}$ & 0.000 \\
\hline Place of residence (urban) & 193 & 25.4 & 366 & 35.8 & 0.000 & 179 & 14.8 & 0.000 & 1243 & 30.0 & 0.010 \\
\hline Region & & & & & 0.364 & & & 0.000 & & & 0.000 \\
\hline Red River Delta & 145 & 19.1 & 190 & 18.6 & & 201 & 16.6 & & 788 & 19.0 & \\
\hline Northern Midlands and Mountains & 41 & 5.4 & 75 & 7.3 & & 191 & 15.8 & & 607 & 14.7 & \\
\hline North and South Central Coast & 138 & 18.2 & 196 & 19.2 & & 340 & 28.1 & & 885 & 21.4 & \\
\hline Central Highlands & 51 & 6.7 & 58 & 5.7 & & 71 & 5.9 & & 240 & 5.8 & \\
\hline South East & 80 & 10.5 & 123 & 12.0 & & 74 & 6.1 & & 470 & 11.4 & \\
\hline Mekong River Delta & 305 & 40.1 & 380 & 37.2 & & 332 & 27.5 & & 1150 & 27.8 & \\
\hline
\end{tabular}

in the NN matching algorithm). The figure was also high for the VHI group. However, the impact was not statistically significant for the entire sample, except for the NN matching estimator.

Furthermore, the magnitude of HI's impact on healthcare utilisation at different providers varied from the VHI to the HSHI group and the group of participants of different HI programmes (full sample). For example, the HI programme contributed to increases of 0.92 in the number of visits at district hospitals for the VHI group, and 0.64 for the full sample (NN matching). While the $\mathrm{HI}$ increased the number of visits at provincial hospitals for the VHI group by 0.55 times per person per year, this figure for the HSHI group was 0.20 (radius matching). The HI programme increased the frequency of use of services at commune health stations among the HSHI group more than other groups (0.53 in kernel and radius matching). Concerning the type of providers, the policy resulted in a substitution effect, which means that the decline of from 0.39 to 0.51 in frequency of visiting

Table 3 Descriptive statistics of outcome variables across different groups

\section{The non-insured subsample}

(1)

\section{Outcome variables} (in last 12 months)

No of outpatient visits

(2)
The insured of heavily
subsidised subsample

(3)
The insured of full sample

(4)

\begin{tabular}{|c|c|c|c|c|c|c|c|c|c|c|c|}
\hline No of inpatient visits & 0.132 & 0.537 & 0.266 & 0.785 & 0.000 & 0.373 & 1.128 & 0.000 & 0.271 & 0.858 & 0.000 \\
\hline $\begin{array}{l}\text { No of visits at commune health } \\
\text { station }\end{array}$ & 0.192 & 0.720 & 0.330 & 1.550 & 0.023 & 0.828 & 2.353 & 0.002 & 0.589 & 1.788 & 0.000 \\
\hline No of visits at district hospital & 0.393 & 1.343 & 1.612 & 4.073 & 0.000 & 1.370 & 3.443 & 0.000 & 1.082 & 3.052 & 0.000 \\
\hline No of visits at provincial hospital & 0.418 & 1.490 & 1.063 & 2.730 & 0.000 & 0.692 & 2.176 & 0.000 & 0.752 & 2.236 & 0.000 \\
\hline $\begin{array}{l}\text { No of visits at state health } \\
\text { facilities }\end{array}$ & 0.834 & 1.923 & 2.758 & 4.551 & 0.000 & 2.178 & 3.939 & 0.000 & 1.930 & 3.622 & 0.000 \\
\hline $\begin{array}{l}\text { No of visits at private health } \\
\text { facilities }\end{array}$ & 1.447 & 2.134 & 0.855 & 2.544 & 0.000 & 0.601 & 1.937 & 0.000 & 0.764 & 2.132 & 0.000 \\
\hline $\begin{array}{l}\text { No of visits at health facility for } \\
\text { medical treatment }\end{array}$ & 2.222 & 2.505 & 3.503 & 4.715 & 0.000 & 3.079 & 4.819 & 0.000 & 2.702 & 4.085 & 0.002 \\
\hline $\begin{array}{l}\text { No of visits at health facility for } \\
\text { health check and consultation }\end{array}$ & 0.329 & 1.027 & 0.574 & 2.151 & 0.004 & 0.664 & 1.920 & 0.000 & 0.589 & 1.866 & 0.000 \\
\hline No of observations & 760 & & 1022 & & & 1209 & & & 4140 & & \\
\hline
\end{tabular}

$\mathrm{VHI}$, voluntary health insurance. 
Table 4 Estimated average treatment effects on the treated (ATTs) of HI scheme on healthcare utilisation across different samples with PSM method in Vietnam

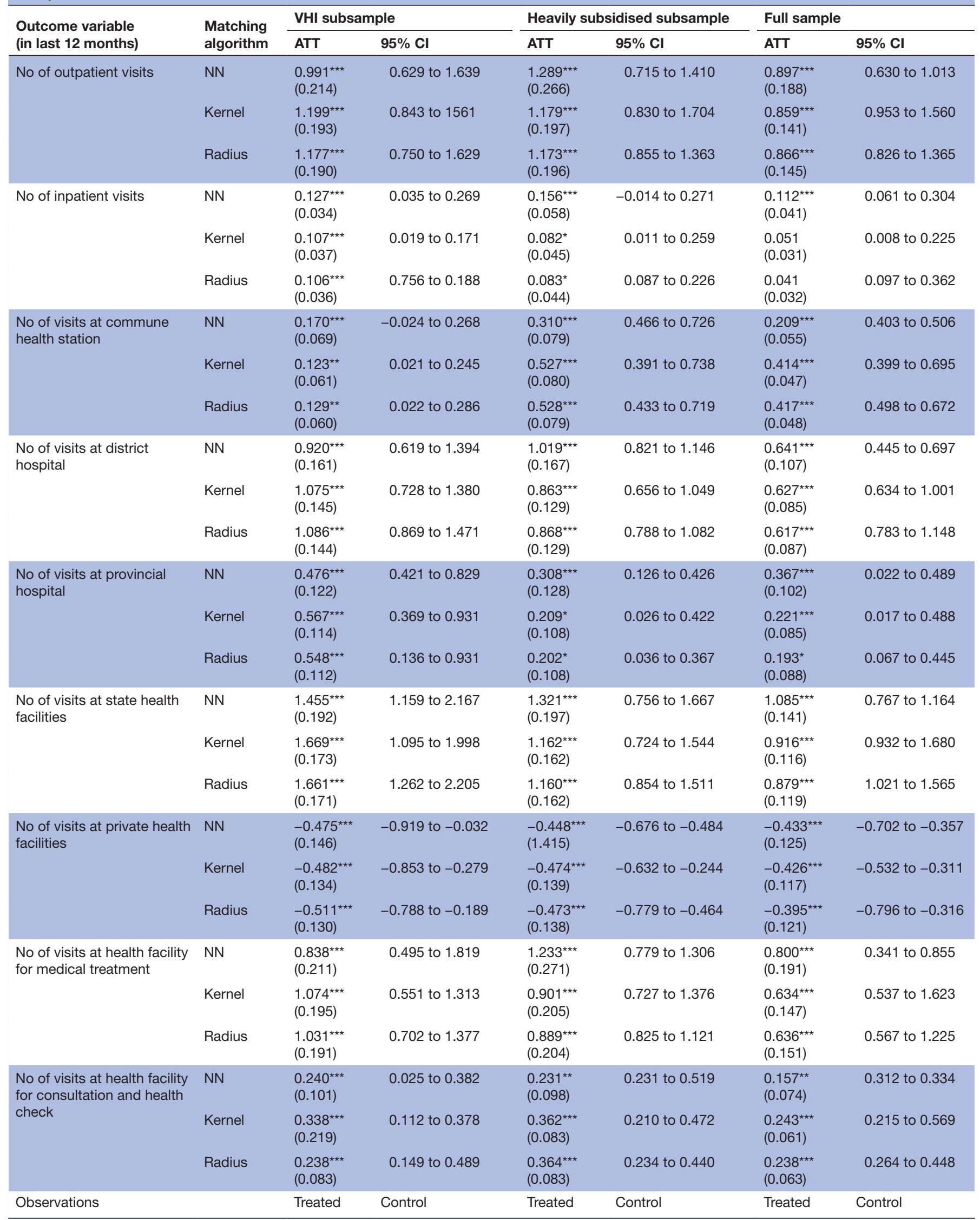


Table 4 Continued

\begin{tabular}{|c|c|c|c|c|c|c|c|}
\hline \multirow{2}{*}{$\begin{array}{l}\text { Outcome variable } \\
\text { (in last } 12 \text { months) }\end{array}$} & \multirow{2}{*}{$\begin{array}{l}\text { Matching } \\
\text { algorithm }\end{array}$} & \multicolumn{2}{|c|}{ VHI subsample } & \multicolumn{2}{|c|}{ Heavily subsidised subsample } & \multicolumn{2}{|c|}{ Full sample } \\
\hline & & ATT & $95 \% \mathrm{Cl}$ & ATT & $95 \% \mathrm{Cl}$ & ATT & $95 \% \mathrm{Cl}$ \\
\hline & $\begin{array}{l}\text { Before } \\
\text { matching }\end{array}$ & 1022 & 760 & 1204 & 760 & 4106 & 760 \\
\hline \multirow[t]{3}{*}{ After matching } & $\mathrm{NN}$ & 575 & 760 & 480 & 760 & 750 & 760 \\
\hline & Kernel & 1002 & 760 & 1173 & 760 & 4093 & 760 \\
\hline & Radius & 1002 & 760 & 1173 & 760 & 4093 & 760 \\
\hline
\end{tabular}

ATT - the average treatment effect on the treated; ATT after performing PSM and bootstrap were presented. SEs in parentheses. ${ }^{\star * *} \mathrm{p}<0.01,{ }^{\star *} \mathrm{p}<0.05$, ${ }^{*} \mathrm{p}<0.1$. $\mathrm{NN}$, nearest-neighbour matching; PSM, propensity score matching; VHI, voluntary health insurance.

private health facilities among the insured transferred to the growth between 0.88 and 1.70 in their intensity of seeking medical services at public facilities. This shift was pronounced among participants of VHI, followed by the HSHI group. In terms of types of visits, the policy was responsible for significant increases from 0.84 to 1.07 in the number of visits for medical treatment among VHI participants and about $0.89-1.23$ among the participants of HSHI programmes. The increased trend was held for the number of health facilities visits to do health checks, which fluctuated around 0.2 across different HI participants.

The quality of the matching process and robustness were checked. The results showed that across different matching algorithms there were sharp reductions in standardised mean bias ranging between $69.54 \%$ and $86.14 \%$ (online supplemental appendix 3). Besides, the hypothesis $\mathrm{H}_{0}$ for no systematic difference in the distribution of covariates between the treatment and control groups after matching was not rejected for VHI and HSHI subsamples with different matching algorithms, and for the full sample with NN matching. In addition, the t-tests for the balance of means that matched the treated and untreated groups in VHI and HSHI subsamples showed insignificant differences for most of the covariates (online supplemental appendix 4).

I calculated Rosenbaum bounds to check the sensitivity of results, which determines the strength of the unobservable heterogeneity that might affect the estimation results. ${ }^{31}$ Rosenbaum boundary estimation results are shown in online supplemental appendix 5. Our results were generally robust except for the ATTs on outcomes of the number of visits at commune health stations and the number of visits at health facilities for health check for some groups. Likewise, under the outcome of the number of outpatient visits, the ATTs were uncertain for the full sample. Similarly, there was hidden bias in the ATTs of the number of visits at the provincial hospital for the HSHI subsample.

\section{DISCUSSION}

This study examined the impact of the Revised HI Law 2014 on the use of healthcare services among different entitlement groups. The results showed that the HI scheme had a positive effect on healthcare utilisation. However, the magnitude of influence on outpatient and inpatient care, types of providers and types of visits was heterogeneous. It was also different between VHI and HSHI groups. The programme has affected the use of outpatient services more than the use of inpatient services. The programme most affected the use of health services at the district level. In terms of using health services at hospitals, the HI scheme had a higher effect on the VHI group than the HSHI group. Concerning the type of providers, the policy had a positive impact on using public health facilities while reducing the frequency of private health facility utilisation.

In particular, the result indicated that the HI scheme was estimated to increase the use of both outpatient and inpatient services for VHI, HSHI groups, and full sample. This finding is consistent with that of Balamiento, who found that the Indigent HI programme for the poor in the Philippines increases the likelihood of outpatient visits by 5.2 to 6.6 percentage points, and inpatient admissions by 3.8 to 4.9 percentage points. ${ }^{1}$ Similarly, in Vietnam, Nguyen found that enrolment in VHI leads to an increase in the number of outpatient and inpatient visits by approximately 0.914 and 0.078 , respectively. ${ }^{21}$ Our results could be related to the fact that according to the Revised HI Law 2014, the poor are entitled to $100 \%$ free of user fees, and the near-poor-95\%, thus may reduce financial barriers to medical service utilisation. ${ }^{37}$ For VHI groups, contributions are based on the family's unit subscription, which reduces premiums for household members. The inability to pay the premium is one of the significant determinants of low uptake of VHI in Vietnam. ${ }^{38}$ Before the Revised HI law was introduced, the HI premium for the VHI group participants was $6 \%$ of the minimum salary. However, after the Revised HI law has been enacted, the family-based contribution has been introduced where the premium of the first member is $4.5 \%$ of the minimum salary. The premiums of the second, third, fourth and fifth members are $70 \%$, $60 \%, 50 \%$ and $40 \%$ of the first member's contribution. ${ }^{37}$ A decreased HI premium is also likely to remove barriers to access to health facilities, and therefore, increasing the rate of services utilisation for both outpatient and inpatient care. 
The increase in healthcare service utilisation might also reveal that the vulnerable groups experience a higher burden of disease or that there might be some moral hazard involved. ${ }^{39-41}$ In particular, in our study the participants in HSHI programmes had higher self-reported illness days (4.98 illness days per year-table 2) than those without HI (1.52 illness days per year). The study of Minh showed a substantial moral hazard among the insured older group, with 1.45 visits per year on average compared with 0.39 times among the uninsured. ${ }^{39}$ In addition, the popularity of fee-for-service payment method that has not been adjusted much in the Revised HI Law might also be the reason for increased visits of health facilities in Vietnam. Indeed, this method triggers supplyinduced demand problem, which means that healthcare providers can give needless diagnosis and treatment to patient. ${ }^{6} 742$ In a qualitative study, Minh and Löfgren ${ }^{42}$ documented: "doctors can determine the diagnosis and treatment protocols, and as such, doctors can suggest patients undergo numerous high-tech diagnostic tests and therapies, many of which might be not so relevant..., the overprovision of tests and therapies and the overuse of high-tech equipment, the increase in patients' length of stay in hospitals is the other tactic hospitals often use to generate revenues".

The study demonstrated that the effect of HI policy on the number of outpatient visits was greater than that of inpatient visits. This may be because of the fact that hospitalisation requires a relative to accompany and care, and other indirect costs which are not covered by HI may arise such as travel costs, informal costs, or some hospital services and medicines, leading to increased out-of-pocket expenditures. ${ }^{42} 43$ Using data from 300 inpatients of different hospitals in northern Vietnam, Vuong ${ }^{43}$ demonstrated that the probability of falling into debt among the insured non-resident patients is approximately $63.3 \%$. In contrast, this figure for the insured resident is only $18 \%$. Besides, informal payments such as 'envelopes' or underthe-table payment are popular in public hospitals in Vietnam. ${ }^{42}$ Concerning accessibility, in a study conducted in remote and mountainous areas in Vietnam, Tran $e t a l^{44}$ demonstrated that distance is a risk factor for access to health services (OR 3.6, 95\% CI 1.5 to 8.3). Therefore, the poor and the near-poor or low-income people are likely to delay inpatient admissions.

The study showed that HI participation increased healthcare services utilisation at district and provincial hospital levels of provider, and the impact was higher for district hospitals. There are several possible explanations for this result. First, this can be explained by the changes in the referral system. Before the revised HI Law 2014, the insured had to visit healthcare providers designated in the HI card; otherwise, they had to pay the full cost of the examination. However, after the revised HI Law has been enacted, the enrollees can go to any district and commune health facility. ${ }^{37}$ Second, the current provider payment system is another possible explanation for the findings. The capitation payment method, which is implemented differently in Vietnam from international features, puts the district hospitals at risk of bearing the full cost of referring patients to the higher healthcare level; therefore, they try to keep the patients. ${ }^{7}$ Third, changes in copayment are likely to contribute to the substantial increase in healthcare utilisation at district hospitals. If the insured receive care from the higher level without referral letter, they have to pay higher copayment rates, for example, $40 \%$ of inpatient medical expenditures at provincial hospitals and $60 \%$ at central hospitals, and they have to pay the full cost of outpatient care. ${ }^{637}$

We observed the intensity of visiting hospitals to be relatively higher for the VHI group than the HSHI group. This result also accords with our earlier observations, which showed that in Vietnam, the people from the lowest quintile and ethnic minorities make up a significant share of commune health station visits. ${ }^{70}$ In particular, in my study, most the enrollees of the HSHI group are from the poorest quintile $(36.7 \%)$, come from rural areas $(85.2 \%)$ and are ethnic minorities (21.3\%) (table 2). In contrast, participants of VHI are better-off with around $22.4 \%$ being from the third quintile group. Besides, approximately $35.8 \%$ of the insured live in urban areas and only $2.2 \%$ of them are ethnic minorities (table 2). Therefore, the insured of the VHI group have more choices of alternative health facilities than those joining HSHI programmes and make greater use of hospitals.

The study also found that the HI programme produced a substitution effect between public and private health facilities. In particular, the decrease in consuming private care has been compensated by an increase in consuming public care. This might be because, in Vietnam, only a small number of private health facilities are covered by HI. ${ }^{6}$ This finding was also reported by Palmer. ${ }^{35}$

With regard to type of visits, I found that ATTs of HI was sensitive to unobserved characteristics for the outcomes of frequency of visiting health facility for consultation and health check. This result is likely to be related to the fact that health check-up is not part of HI benefits package. ${ }^{37}$ Besides, although preventive consultation services are financed by state budget, investment in the primary care level in Vietnam is still modest. ${ }^{10}$

The most important limitation of this study lies in the fact that using the PSM method to measure the HI scheme's causal effect, the estimated results may be biased if variables affecting both the outcome and treatment status are omitted: unobserved confounders. Specifically, the study failed to control supply-side factors, such as the quality and availability of health workers, attitude of medical staff towards patients, availability of medicines and equipment in different health facilities, and the number and distribution of healthcare facilities between regions. Other health security problems, such as re-emerging communicable diseases, pollution and natural disasters, happened around the time of the Revised HI Law's introduction, were also not considered in this study. For example, measles and dengue fever outbreaks, and $\mathrm{A}(\mathrm{H} 5 \mathrm{~N} 1)$ avian influenza in humans 
occurred in 2014. ${ }^{45}$ Also, the introduction of Government Decree 16/ND-CP 2015 on the autonomy of public hospitals, which is likely to be responsible for the increase in healthcare service utilisation, ${ }^{42}$ was not controlled. Bias associated with self-reported data is another limitation of this study. Finally, the interval after the revision of the law may have been short to evaluate its impacts. Future research may address these issues using longitudinal data with other specifications, such as instrumental variables or difference-in-difference.

\section{CONCLUSION}

The HI scheme significantly increased both outpatient and inpatient healthcare utilisation for different HI groups of interest. The findings have several practical implications. The government could continue increasing HI coverage for low coverage rate groups such as informal sector workers, farmers, fishers and other near-poor groups by subsidising premium contributions. Besides, Vietnam Social Security (VSS) might regularly monitor hospitals in terms of drug lists and medical services reimbursed by the HI fund to avoid possible supply-induced demand problem. The study also found that the effect was more marked for the district hospital level of care than the provincial level. This finding suggests the government could give priorities for the primary level of care by investing in health resources, including health workers, equipment, medicines and appropriate distribution of health facilities to optimise the referral system. The results also demonstrated that the participants of the VHI group visited hospitals more intensively. This suggests that VSS could strengthen monitoring hospitals to ensure appropriate examination and treatment. VSS might also adjust payment method aiming to combine capitation and diagnostic-related group methods. I also found the substitution effect of using private health services for state health services. There is potential room for reducing the overload of tertiary care level by expanding HI contracts and enhancing collaboration with the private health sector.

Acknowledgements The author would like to show appreciation to Mr Yme Van Den Berg and Pierre Pratley who are senior advisors of department Global Health, Royal Tropical Institute, KIT Health, P.0. Box 95001, 1090 HA, Amsterdam, The Netherlands for editing the manuscript. The author is grateful to the Royal Tropical Institute (KIT) and the Thai Nguyen University of Economics and Business Administration and General Statistics Office of Vietnam (GSO) for their support and cooperation.

Contributors TTTN designed the study, collected and extracted data, performed statistical analysis and wrote the manuscript.

Funding The authors have not declared a specific grant for this research from any funding agency in the public, commercial or not-for-profit sectors.

Competing interests None declared.

Patient consent for publication Not required.

Ethics approval This study is a secondary analysis. The data contained in the article are publicly available from the General Statistics Office of Vietnam.

Provenance and peer review Not commissioned; externally peer reviewed.

Data availability statement Data available on reasonable request.
Open access This is an open access article distributed in accordance with the Creative Commons Attribution Non Commercial (CC BY-NC 4.0) license, which permits others to distribute, remix, adapt, build upon this work non-commercially, and license their derivative works on different terms, provided the original work is properly cited, appropriate credit is given, any changes made indicated, and the use is non-commercial. See: http://creativecommons.org/licenses/by-nc/4.0/.

ORCID iD

Nguyen Thi Thu Thuong http://orcid.org/0000-0003-3821-2642

\section{REFERENCES}

1 Balamiento NC. The impact of social health insurance on healthcare utilization outcomes: evidence from the indigent program of the Philippine National Health Insurance. International Institute of Social Studies, 2018.

2 Azam M. Does social health insurance reduce financial burden? Panel data evidence from India. World Dev 2018;102:1-17.

3 Wagner N, Quimbo S, Shimkhada R, et al. Does health insurance coverage or improved quality protect better against out-of-pocket payments? Experimental evidence from the Philippines. Soc Sci Med 2018;204:51-8.

4 General Statistics Office. Social insurance, health insurance and unemployment insurance. Available: https://www.gso.gov.vn/SLTK/ [Accessed March 12, 2019].

5 World Health Organization and Vietnam Ministry of Health. Health financing strategy of Vietnam (2016-2025) 2016;47.

6 Japan International Cooperation Agency (JICA). KRI International Corp. basic information survey for basic health service package and provider payment mechanism in Viet Nam, 2017.

7 Somanathan A, Tandon A, Dao HL, et al. Moving toward universal coverage of social health insurance in Vietnam: assessment and options. The World Bank, 2014.

8 Le N, Groot W, Tomini SM, et al. Health insurance and patient satisfaction: evidence from the poorest regions of Vietnam. MERIT Working Papers 2018-040, United Nations University - Maastricht Economic and Social Research Institute on Innovation and Technology (MERIT), 2018.

9 General Statistical Ofice. Result of the Vietnam household living standards survey 2016. Section 3-health and health care. Hanoi, Vietnam: Statistical Publishing House, 2018: 153-214.

10 The World Bank. Quality and Equity in Basic Health Care Services in Vietnam: Findings from the 2015 Vietnam District and Commune Health Facility Survey. The World Bank, 2016.

11 Matsushima M, Yamada H. Public health insurance in Vietnam towards universal coverage: identifying the challenges, issues, and problems in its design and organisational practices. J Int Heal 2014;29:289-97.

12 Vietnam Social Insurance. Health insurance: participants and contribution rates. Available: https://baohiemxahoidientu.vn/bhxh/ bhyt-doi-tuong-tham-gia-va-muc-dong.html [Accessed 15 Jan 2020].

13 Giedion U, Alfonso EA, Díaz Y. The impact of UHC in the developing world. A review of the existing evidence2013.

14 Hangoma P, Robberstad B, Aakvik A. Does free public health care increase utilization and reduce spending? Heterogeneity and long term effects. World Dev 2018;101:334-50.

15 Zhao $\mathrm{H}$. China's health insurance reform and disparities in healthcare utilization and costs: a longitudinal analysis. The Pardee RAND Graduate School, 2014.

16 Sparrow R, Suryahadi A, Widyanti W. Social health insurance for the poor: targeting and impact of Indonesia's Askeskin Program. Jakarta: SMERU Research Institute, 2010.

17 Bauhoff S, Hotchkiss DR, Smith O. The impact of medical insurance for the poor in Georgia: a regression discontinuity approach. Health Econ 2011;20:1362-78.

18 Thornton RL, Hatt LE, Field EM, et al. Social security health insurance for the informal sector in Nicaragua: a randomized evaluation. Health Econ 2010;19 Suppl:181-206.

19 Wagstaff A. Estimating health insurance impacts under unobserved heterogeneity: the case of Vietnam's health care fund for the poor. Health Econ 2010;19:189-208.

20 Sepehri A, Sarma S, Simpson W. Does non-profit health insurance reduce financial burden? Evidence from the Vietnam Living Standards Survey Panel. Health Econ 2006;15:603-16.

21 Nguyen CV. The impact of voluntary health insurance on health care utilization and out-of-pocket payments: new evidence for Vietnam. Health Econ 2012;21:946-66. 
22 Nguyen C. The impact of health insurance programs for children: evidence from Vietnam. Health Econ Rev 2016;6:16.

23 Khandker SR, Koolwal GB, Samad HA. Handbook on impact evaluation: quantitative methods and practices. Washington, DC.: The World Bank, 2010.

24 Mebratie AD, Sparrow R, Yilma Z, et al. The impact of Ethiopia's pilot community based health insurance scheme on healthcare utilization and cost of care. Soc Sci Med 2019;220:112-9.

25 Ravallion M. The mystery of the vanishing benefits: an introduction to impact evaluation. World Bank Econ Rev 2001;15:115-40.

26 Grilli L, Rampichini C. Propensity scores for the estimation of average treatment effects in observational studies. Training sessions on causal inference. Bristol, 2011.

27 Axelson $\mathrm{H}$, Bales S, Minh PD, et al. Health financing for the poor produces promising short-term effects on utilization and out-ofpocket expenditure: evidence from Vietnam. Int $J$ Equity Health 2009;8:20.

28 Saad-Haddad G, DeJong J, Terreri N, et al. Patterns and determinants of antenatal care utilization: analysis of national survey data in seven countdown countries. J Glob Health 2016;6:010404.

29 Adane M, Mengistie B, Mulat W, et al. Utilization of health facilities and predictors of health-seeking behavior for under-five children with acute diarrhea in slums of Addis Ababa, Ethiopia : a communitybased cross-sectional study. J Heal Popul Nutr 2017;36:1-12.

30 Rosenbaum PR. Observational studies and nonrandomized experiments. Handb Stat 1996;13:181-97.

31 Rosenbaum PR. Observational studies. New York: Springer, 2002

32 Sparrow R, Suryahadi A, Widyanti W. Social health insurance for the poor: targeting and impact of Indonesia's Askeskin programme. Soc Sci Med 2013;96:264-71.

33 Rosenbaum PR, Rubin DB. The central role of the propensity score in observational studies for causal effects. Biometrika 1983;70:41-55.

34 Gustafsson-Wright E, Popławska G, Tanović Z, et al. The impact of subsidized private health insurance and health facility upgrades on healthcare utilization and spending in rural Nigeria. Int $J$ Health Econ Manag 2018;18:221-76.

35 Palmer MG. Inequalities in universal health coverage: evidence from Vietnam. World Dev 2014;64:384-94.

36 Rosenbaum PR, Rubin D. Constructing a control group using multivariate matched sampling methods that incorporate the propensity score. Am Stat 1985;39:33-8.

37 The National Assembly. Law amendments to the law on health insurance. No: 46/2014/QH13 2014:4-17.

38 Nga NTT. Family-based social health insurance for informal workers in Vietnam: willingness to pay and its determinants. PhD diss. Queensland University of Technology, 2018.

39 Minh NT. Moral hazard and adverse selection in health insurances, evidence from a transitional economy. Singapore Econ Rev 2014:59:1-21.

40 Phuong NV. Moral hazard problems under public health insurance evidence from Vietnam. VNU J Econ Busines 2013;29:56-66.

41 Nguyen DN, Nguyen LH, Nguyen CT, et al. Health status and health service utilization among Vietnamese farmers in a mountainous province. Int J Environ Res Public Health 2019;16:4768-12.

42 Minh VTH, Löfgren K. An institutional analysis of the fiscal autonomy of public hospitals in Vietnam. Asia Pacific Policy Stud 2019;6:90-107.

43 Vuong QH. Be rich or don't be sick: estimating Vietnamese patients' risk of falling into destitution. Springerplus 2015;4:2-31.

44 Tran BX, Nguyen LH, Nong VM, et al. Health status and health service utilization in remote and mountainous areas in Vietnam. Health Qual Life Outcomes 2016;14:1-9.

45 Vietnam Ministry of Health, Health Partnership Group. Joint annual health review 2015. Strengthening primary health care at the grassroots towards universal health coverage, 2016.

46 Ministry of Health. Health Statistics Yearbook, Vietnam. Ha Noi: Medical Publisher, 2017. 